Pacific Journal of Mathematic 


\section{ARITHMETIC SUMS THAT DETERMINE LINEAR CHARACTERS ON $\Gamma(N)$}

\section{RANDY TULER}

A new class of arithmetic sums is defined and used to explicitly exhibit linear characters on $\Gamma(N)$, the principal congruence subgroup of level $N$ in $S L(2, \boldsymbol{Z})$. As an application of this, we get a striking result on the structure of the commutator subgroup of $\Gamma(N)$.

1. Introduction. Let $\alpha, \beta, N \in Z$ with $N>1,(\alpha, \beta)=1$, and $\alpha-1 \equiv \beta \equiv 0(\bmod N)$. For any function $\chi: Z / N \boldsymbol{Z} \rightarrow \boldsymbol{R}$ define the arithmetic sum

$$
t_{N, \chi}(\alpha, \beta)=\left\{\begin{array}{cc}
\sum_{\substack{k=1 \\
k \neq 0(\bmod N)}}^{\beta-1} \chi\left(\left[\frac{k \alpha}{\beta}\right](\bmod N)\right), & \beta>0 \\
0 & , \quad \beta=0 \\
-t_{N, \chi}(\alpha,-\beta) & , \quad \beta<0
\end{array}\right.
$$

where [ ] denotes the integer part.

EXAMPLE 1. With $N=2, \chi(0)=1$, and $\chi(1)=-1$ we have $\left.t_{2, x}(1,2)=\chi([1 / 2])=\chi(0)=1 ; t_{2, x}(5,8)=\chi([5 / 8])+\chi(15 / 8]\right)+\chi([25 / 8])+$ $\chi([35 / 8])=\chi(0)+\chi(1)+\chi(3)+\chi(4)=1-1-1+1=0$.

The principal congruence subgroup of level $N$ in $\mathrm{SL}(2, Z)$ is

$$
\Gamma(N)=\{A \in \mathrm{SL}(2, Z) \mid A \equiv I(\bmod N)\} .
$$

After preliminary work in $\S 2$ we prove

THEOREM 1. If $\sum_{g \in Z / N Z} \chi(g)=0$, then the $\operatorname{map} \Gamma(N) \rightarrow C$ defined by

$$
\left(\begin{array}{ll}
\delta & \gamma \\
\beta & \alpha
\end{array}\right) \longrightarrow \exp \left(i t_{N, \chi}(\alpha, \beta)\right)
$$

is a linear character on $\Gamma(N)$.

See [1] for the relation of this result to modular forms, knot theory, and recent work of J. B. Wagoner on diffeomorphisms of manifolds.

In $\S 4$, as an application of Theorem 1 , we get a new result on the structure of the commutator subgroup of $\Gamma(N)$.

2. Preliminaries. We develop an analy tic expression for $t_{N, x}(\alpha, \beta)$ 
that is instrumental in the proof of Theorem 1. Let $p, q, r \in \boldsymbol{R}^{2}$, and let $\mathfrak{I}(p, q)$ and $\mathfrak{I}(p, q)+r$ denote the directed line segment from $p$ to $q$ and its translation by $r$ respectively. Denote the oriented parallelogram in $R^{2}$ with sides $\left.\mathfrak{I}((0,1),(0,0)), p\right), \mathfrak{l}((0,0), p), \mathfrak{l}((0,0)$, $(0,1))+p$, and $\mathfrak{I}(p,(0,0))+(0,1)$ by $\mathscr{R}(p)$. Define the function $\psi$ on $\boldsymbol{Z} / N \boldsymbol{Z}$ by

$$
\psi g()= \begin{cases}1, & g \neq \equiv(\bmod N) \\ 0, & g \equiv 0(\bmod N)\end{cases}
$$

Lemma 1. Let $\left\{\left(m_{k}, n_{k}\right)\right\}$ be the points of $\boldsymbol{Z} \oplus \boldsymbol{Z}$ contained in the convex hull of $\mathscr{R}((\beta, \alpha))$. Then

$$
\sum_{k} \psi\left(m_{k}\right) \chi\left(n_{k}-1\right)=t_{N, \chi}(\alpha,|\beta|) .
$$

Proof. For $\beta>0$, the set of points of $Z \oplus Z$ in the interior of the convex hull of $\mathscr{R}((\beta, \alpha))$ is precisely

$$
\left\{\left(k,\left[\frac{k \alpha}{\beta}\right]+1\right) \mid 0<k<\beta\right\}
$$

since $(\alpha, \beta)=1$. The four points of $\boldsymbol{Z} \oplus \boldsymbol{Z}$ on $\mathscr{R}((\beta, \alpha))$ have $m_{k} \equiv 0$ $(\bmod N)$. Consequently,

$$
\begin{aligned}
\sum_{k} \psi\left(m_{k}\right) \chi\left(n_{k}-1\right) & =\sum_{k=1}^{\beta-1} \psi(k) \chi\left(\left[\frac{k \alpha}{\beta}\right]\right) \\
& =\sum_{\substack{k=1 \\
k \neq 0(\bmod N)}}^{\beta-1} \chi\left(\left[\frac{k \alpha}{\beta}\right]\right)=t_{N, \chi}(\alpha, \beta) .
\end{aligned}
$$

The cases $\beta=0$ and $\beta<0$ are handled similarly.

For the rest of the paper, we assume $\sum_{g \in Z_{/ N} Z} \chi(g)=0$.

LEMma 2. There is an elliptic function $f$ (see [2]) with the following properties:

(1) The period lattice of $f$ is $N Z \oplus N Z$.

(2) The pole set of $f$ is $S=\{(m, n) \in \boldsymbol{Z} \oplus \boldsymbol{Z} \mid m \neq \equiv 0(\bmod N)\}$.

(3) If $r=(m, n) \in S$, then the residue of $f$ at $r$ is $\chi(n-1)$.

Proof. The pole set $S$ is well-defined modulo the period lattice $N \boldsymbol{Z} \oplus N \boldsymbol{Z}$. The set of assigned residues is well-defined modulo $N \boldsymbol{Z} \oplus N \boldsymbol{Z}$ since $\chi$ is defined on $\boldsymbol{Z} / N \boldsymbol{Z}$. Furthermore, the sum of the assigned residues over a fundamental region of $N \boldsymbol{Z} \oplus N Z$ vanishes because $\sum_{g \in Z / N} \chi(g)=0$. Under these conditions we may apply the Riemann-Roch theorem to assert the existence of $f$. 
Lemma 3. The integral $\int_{\mathscr{E}((\beta, \alpha))} f$ is well-defined.

Proof. No point of $S$ is on $\mathscr{R}((\beta, \alpha))$.

Proposition 1. $2 \pi i t_{N, \mathrm{x}}(\alpha, \beta)=\int_{\pi(\langle\beta, \alpha))} f$.

Proof. Follows immediately from the preceding theree lemmas and the residue theorem.

3. Proof of Theorem 1. For $A \in \Gamma(N)$, let $\mathscr{R}((\beta, \alpha)) A$ denote the parallelogram in $\boldsymbol{R}^{2}$ obtained by applying the linear transformation $A$ pointwise to $\mathscr{R}((\beta, \alpha))$.

LEMMA 4. If $A \in \Gamma(N)$, then

$$
\int_{\mathscr{R}((\beta, \alpha)) A} f=\int_{\mathscr{R}((\beta, \alpha))} f .
$$

Proof. $A$ fixes the lattice $\boldsymbol{Z} \oplus \boldsymbol{Z}$ modulo $N \boldsymbol{Z} \oplus N Z$. Consequently, the sum of the residues of $f$ inside $\mathscr{R}((\beta, \alpha)) A$ is precisely the sum of the residues inside $\mathscr{R}((\beta, \alpha))$. Observing that $A$ preserves orientation and applying the residue theorem finishes the proof.

Lemma 5. If $A=\left(\begin{array}{ll}\delta & \gamma \\ \beta & \alpha\end{array}\right) \in \Gamma(N)$, then

$$
2 \pi i t_{N, \mathrm{x}}(\alpha, \beta)=\int_{i(10,1) A)} f .
$$

Proof. $(0,1) A=(\beta, \alpha)$, so $\mathscr{R}((0,1) A)=\mathscr{R}((\beta, \alpha))$. Apply Proposition 1 .

Proof of Theorem 1. By Lemma 5, it suffices to show

$$
\int_{\mathscr{S}((0,1) A)} f+\int_{\mathscr{R}((0,1) B)} f=\int_{\mathscr{S}((0,1) B A)} f
$$

for $A, B \in \Gamma(N)$. By Lemma 4,

$$
\int_{\mathscr{R}((0,1) A)} f+\int_{\mathscr{R}((0,1) B)} f=\int_{\mathscr{R}((0,1) A)} f+\int_{\mathscr{R}((0,1) B) A} f .
$$

Breaking up the path of integration into directed line segments, we write the right hand side of the last expression as 


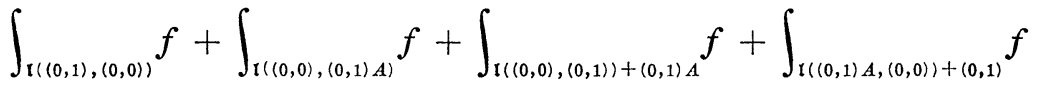

$$
\begin{aligned}
& +\int_{\mathbb{U}((0,1) A,(0,0))} f+\int_{\mathbb{I}(0,0),(0,1) B A)} f+\int_{\mathbb{U}((0,0),(0,1) A)+(0,1) B A} f \\
& +\int_{\mathfrak{r}((0,1) B A,(0,0))+(0,1) A} f \text {. }
\end{aligned}
$$

Since $A$ and $B$ fix $(0,1)$ modulo $N Z \oplus N Z$ and $f$ has period lattice $N Z \oplus N Z$, we have the following relations:

$$
\begin{gathered}
\int_{\mathfrak{I}((0,0),(0,1) A)+(0,1) B A} f+\int_{\mathfrak{I}(0,1) A,(0,0))+(0,1)} f=0 \\
\int_{\mathfrak{U}((0,0),(0,1))+(0,1) A} f=\int_{\mathfrak{I}((0,0),(0,1))+(0,1) B A} f \\
\int_{\mathfrak{I}((0,0),(0,1) A)} f+\int_{\mathfrak{I}(0,1) A,(0,0))} f=0 \\
\int_{\mathfrak{U}((0,1) B A,(0,0))+(0,1) A} f=\int_{\mathfrak{I}(0,1) B A,(0,0))+(0,1)} f .
\end{gathered}
$$

Applying (1), (2), (3), and (4) to the preceding sum of eight integrals gives

$$
\begin{aligned}
& \int_{\mathbb{I}((0,1),(0,0))} f+\int_{\mathbb{I}((0,0),(0,1) B A)} f \\
& \quad+\int_{\mathbb{T}((0,0),(0,1))+(0,1) B A} f+\int_{\mathbb{I}(0,1) B A,(0,0))+(0,1)} f .
\end{aligned}
$$

To finish the proof of Theorem 1 , we recognize this last sum as

$$
\int_{\Omega(1(0,1) B A)} f \text {. }
$$

EXAMPle 2. Let $N=2, \chi(0)=1$, and $\chi(1)=-1$. We have $\left(\begin{array}{ll}1 & 0 \\ 2 & 1\end{array}\right),\left(\begin{array}{rr}13 & 8 \\ 8 & 5\end{array}\right) \in \Gamma(2)$ and $\left(\begin{array}{ll}1 & 0 \\ 2 & 1\end{array}\right)\left(\begin{array}{rr}13 & 8 \\ 8 & 5\end{array}\right)=\left(\begin{array}{rr}13 & 8 \\ 34 & 21\end{array}\right)$. Since $\sum_{g \in Z / 2 Z} \chi(g)=$ 0 , Theorem 1 asserts that $t_{2, x}(21,34)=t_{2, x}(1,2)+t_{2, x}(5,8)$. From Example 1, $t_{2, x}(1,2)=1$ and $t_{2, x}(5,8)=0$. Therefore $t_{2, x}(21,34)=$ $1+0=1$. Checking this directly gives

$$
\begin{aligned}
t_{2, \chi}(21,34)= & \sum_{\substack{k=1 \\
k \neq 0=\bmod 2)}}^{33} \chi\left(\left[\frac{21 k}{34}\right]\right) \\
= & \chi(0)+\chi(1)+\chi(3)+\chi(4)+\chi(5)+\chi(6)+\chi(8) \\
& +\chi(9)+\chi(10)+\chi(11)+\chi(12)+\chi(14)+\chi(15) \\
& +\chi(16)+\chi(17)+\chi(19)+\chi(20)=1-1-1+1-1 \\
& +1+1-1+1-1+1+1-1+1-1-1+1=1 .
\end{aligned}
$$


4. A structural theorem for the commutator subgroup of $\Gamma(N)$. Let $\Gamma(N)^{\prime}$ denote the commutator subgroup of $\Gamma(N)$.

Theorem 2. Suppose $\left(\begin{array}{ll}\delta & \gamma \\ \beta & \alpha\end{array}\right) \in \Gamma(N)^{\prime}$ with $\beta>0$. Then for any $m \in Z$ there are precisely $1 / N(\beta-\beta / N)$ elements of the set $C=$ $\{[k \alpha / \beta]\}_{\substack{k=1 \\ k \neq 0(\bmod N)}}^{\beta-1}$ that satisfy $[k \alpha / \beta] \equiv m(\bmod N)$.

Proof. For a fixed $m \neq \equiv(\bmod N)$, define

$$
\chi(g)=\left\{\begin{array}{rr}
1, & g \equiv 0(\bmod N) \\
-1, & g \equiv \bmod N) \\
0, & \text { otherwise }
\end{array}\right.
$$

Using Theorem 1 along with the observation that the image of $\Gamma(N)^{\prime}$ under a linear character is trivial, we deduce that the number of elements of $C$ that satisfy $[k \alpha / \beta] \equiv m(\bmod N)$ is the same as the number of elements of $C$ that satisfy $[k \alpha / \beta] \equiv 0(\bmod N)$. Since this holds for any $m \neq 0(\bmod N)$, and since there are precisely $\beta-\beta / N$ elements in $C$, we get the theorem.

Corollary. If $\left(\begin{array}{ll}1 & 0 \\ \beta & 1\end{array}\right) \in \Gamma(N)^{\prime}$, then $\beta=0$.

Proof. If $\beta>0$, then every element of $C$ vanishes. By Theorem $2,\left(\begin{array}{ll}1 & 0 \\ \beta & 1\end{array}\right) \notin \Gamma(N)^{\prime}$. If $\beta<0$, use the preceding argument on $\left(\begin{array}{ll}1 & 0 \\ \beta & 1\end{array}\right)^{-1} \in$ $\Gamma(N)^{\prime}$.

\section{REFERENCES}

1. R. Tuler, Topological construction of multiplier systems on $\Gamma(N)$, dissertation, University of California at Berkeley, 1979.

2. S. Lang, Elliptic Functions, Addison-Wesley, 1973.

3. R. Rankin, The modular group and its subgroups, Ramanujan Institute, 1969.

Received October 30, 1979. This work is a part of the author's doctoral dissertation written under the supervision of J.B. Wagoner at the University of California, Berkeley.

UNIVERSity of Georgia

Athens, GA 30602 



\section{PACIFIC JOURNAL OF MATHEMATICS}

\section{EDITORS}

DONALD BABBITT (Managing Editor)

University of California

Los Angeles, CA 90024

Hugo RossI

University of Utah

Salt Lake City, UT 84112

C. C. MOORE and ANDREW OGG

University of California

Berkeley, CA 94720

\section{J. DugunduI}

Department of Mathematics

University of Southern California

Los Angeles, CA 90007

R. Finn and J. Milgram

Stanford University

Stanford, CA 94305

\section{ASSOCIATE EDITORS}
E. F. BeCKenBACH
B. H. NeumanN
F. WOLF
K. YosHIDA

\section{SUPPORTING INSTITUTIONS}

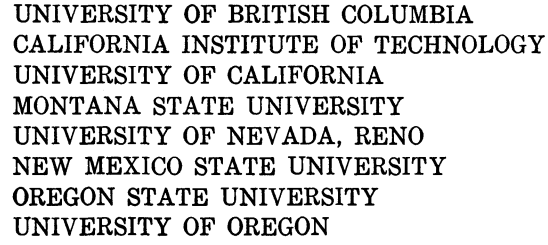

UNIVERSITY OF BRITISH COLUMBIA CALIFORNIA INSTITUTE OF TECHNOLOGY UNIVERSITY OF CALIFORNIA

MONTANA STATE UNIVERSITY

UNIVERSITY OF NEVADA, RENO

NEW MEXICO STATE UNIVERSITY

OREGON STATE UNIVERSITY UNIVERSITY OF OREGON

\author{
UNIVERSITY OF SOUTHERN CALIFORNIA \\ STANFORD UNIVERSITY \\ UNIVERSITY OF HAWAII \\ UNIVERSITY OF TOKYO \\ UNIVERSITY OF UTAH \\ WASHINGTON STATE UNIVERSITY \\ UNIVERSITY OF WASHINGTON
}

The Supporting Institutions listed above contribute to the cost of publication of this Journal, but they are not owners or publishers and have no responsibility for its content or policies.

Mathematical papers intended for publication in the Pacific Journal of Mathematics should be in typed form or offset-reproduced, (not dittoed), double spaced with large margins. Please do not use built up fractions in the text of the manuscript. However, you may use them in the displayed equations. Underline Greek letters in red, German in green, and script in blue. The first paragraph or two must be capable of being used separately as a synopsis of the entire paper. Please propose a heading for the odd numbered pages of less than 35 characters. Manuscripts, in triplicate, may be sent to any one of the editors. Please classify according to the scheme of Math. Reviews, Index to Vol. 39. Supply name and address of author to whom proofs should be sent. All other communications should be addressed to the managing editor, or Elaine Barth, University of California, Los Angeles, California, 90024.

50 reprints to each author are provided free for each article, only if page charges have been substantially paid. Additional copies may be obtained at cost in multiples of 50 .

The Pacific Journal of Mathematics is issued monthly as of January 1966. Regular subscription rate: $\$ 84.00$ a year (6 Vols., 12 issues). Special rato: $\$ 42.00$ a year to individual members of supporting institutions.

Subscriptions, orders for numbers issued in the last three calendar years, and changes of address shoud be sent to Pacific Journal of Mathematics, P.O. Box 969, Carmel Valley, CA 93924, U.S.A Old back numbers obtainable from Kraus Periodicals Co., Route 100, Millwood, NY 10546.

PUBLISHED BY PACIFIC JOURNAL OF MATHEMATICS, A NON-PROFIT CORPORATION

Printed at Kokusai Bunken Insatsusha (International Academic Printing Co., Ltd.). 8-8, 3-chome, Takadanobaba, Shinjuku-ku, Tokyo 160, Japan.

Copyright (C) 1980 by Pacific Jounal of Mathematics Manufactured and first issued in Japan 


\section{Pacific Journal of Mathematics \\ Vol. 90, No. $2 \quad$ October, 1980}

Frank Hayne Beatrous, Jr., Hölder estimates for the $\bar{\partial}$ equation with a support condition ..................................... 249

Charles L. Belna, Michael Jon Evans and Paul Humke, Planar continua

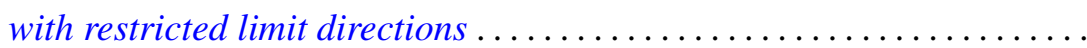

Leon Brown and Takashi Ito, Classes of Banach spaces with unique isometric preduals................................. 261

V. K. Deshpande, Completions of Noetherian hereditary prime rings ..... . 285

Deepak Dhar, Asymptotic enumeration of partially ordered sets . . . . . . . 299

Zeev Ditzian, On interpolation of $L_{p}[a, b]$ and weighted Sobolev

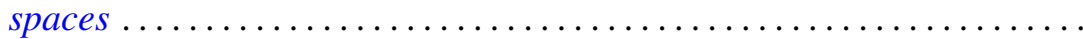

Andrew George Earnest, Congruence conditions on integers represented by

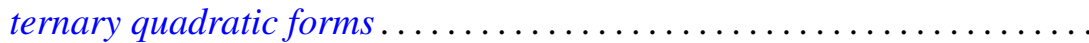

Melvin Faierman, Bounds for the eigenfunctions of a two-parameter system of ordinary differential equations of the second order ..............

Hector O. Fattorini, Vector-valued distributions having a smooth

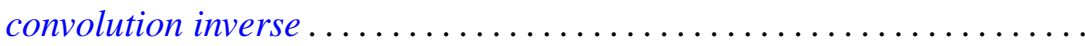

Howard D. Fegan, The spectrum of the Laplacian on forms over a Lie

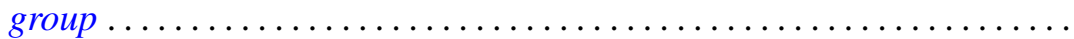

Gerald Leonard Gordon, On the degeneracy of a spectral sequence associated to normal crossings..

S. Madhavan, On bisimple weakly inverse semigroups ... 397

Françoise Mathot, On the decomposition of states of some

Roger McCann, Embedding asymptotically stable dynamical systems into radial flows in $l_{2}$

Michael L. Mihalik, Ends of fundamental groups in shape and proper homotopy...............................

Samuel Murray Rankin, III, Boundary value problems for partial functional differential equations .

Randy Tuler, Arithmetic sums that determine linear characters on $\Gamma(N)$

Jeffrey D. Vaaler, On linear forms and Diophantine approximation ..

G. P. Wene, Alternative rings whose symmetric elements are nilpotent or a right multiple is a symmetric idempotent. . 